\title{
Effect of Pistacia atlantica kurdica gum on diabetic gastroparesis symptoms: a randomized, triple-blind placebo-controlled clinical trial
}

\author{
Fatemeh Mahjoub ${ }^{1}$, Roshanak Salari², Mahdi Yousefi ${ }^{3}$, Masoud Mohebbi ${ }^{4}$, Azadeh Saki ${ }^{5}$, Kambiz Akhavan \\ Rezayat $^{6}$
}

1 M.D., Ph.D. Candidate of Persian Medicine, Department of Persian Medicine, School of Persian and Complementary Medicine, Mashhad University of Medical Sciences, Mashhad, Iran

${ }^{2}$ Ph.D. of Drug Control, Assistant Professor, Department of Pharmaceutical Sciences in Persian Medicine, School of Persian and Complementary Medicine, Mashhad University of Medical Sciences, Mashhad, Iran

${ }^{3}$ M.D., Ph.D. of Persian Medicine, Assistant Professor, Department of Persian Medicine, School of Persian and Complementary Medicine, Mashhad University of Medical Sciences, Mashhad, Iran

${ }^{4}$ M.D., Assistant Professor, Endocrine Research Center, Mashhad University of Medical Sciences, Mashhad, Iran

${ }^{5}$ Ph.D. of Biostatistics, Assistant Professor, Department of Epidemiology and Biostatistics, School of Health, Mashhad University of Medical Sciences, Mashhad, Iran

${ }^{6}$ M.D., Assistant Professor, Department of Internal Medicine, School of Medicine, Mashhad University of Medical Sciences, Mashhad, Iran

\section{Type of article: Original}

\begin{abstract}
Background: Gastroparesis is a recognized problem of type 1 and 2 diabetes mellitus that is defined by delayed gastric emptying. Due to insufficient satisfaction of current treatments, the use of complementary and alternative medicine in this field seems essential. According to Persian medicine, Pistacia atlantica gum has proper effect on gastrointestinal disorder specially stomach diseases.

Objective: The aim of this study was to assess the effect of Pistacia atlantica gum on diabetic gastroparesis symptoms.

Methods: A triple-blind randomized placebo-controlled trial on subjects with diabetic gastroparesis was conducted at the clinic of Imam Reza Hospital in Mashhad city in Iran, from November 2016 to May 2017. Fiftyfour patients ( $16.7 \%$ males and $83.3 \%$ females) enrolled in the 8 -week study and were randomly divided into two groups of intervention Pistacia atlantica and placebo groups. Both of the groups had received current dietary advice. Severity of gastroparesis symptoms was assessed with a Gastroparesis cardinal symptom index (GCSI) questionnaire. SPSS software version 16 was used to analyze the data and Generalized Estimating Equation (GEE) model, Independent-samples t-test, Paired-samples t-test, Mann-Whitney U test, and Wilcoxon signedrank test were used to assess variables.

Results: All gastroparesis symptoms of patients (14.6\% diabetes type 1 and $85.4 \%$ diabetes type 2 ) including nausea /vomiting, postprandial fullness/early satiety, and bloating were significantly declined in each group during study $(\mathrm{p}<0.0001)$. Pistacia atlantica gum significantly reduced severity of gastroparesis symptoms including Postprandial fullness/early satiety $(p=0.04)$, Bloating $(p<0.0001)$, and GCSI scores $(p=0.001)$ versus placebo. Systolic blood pressure $(\mathrm{p}=0.006)$, BMI $(\mathrm{p}=0.018)$, and HbAlc $(\mathrm{p}=0.038)$ significantly decreased in the Pistacia atlantica group after the intervention.

Conclusion: This study showed that daily consumption of Pistacia atlantica gum for one month improves diabetic gastroparesis symptoms.
\end{abstract}

\section{Corresponding author:}

Assistant Professor Dr. Kambiz Akhavan Rezayat, Department of Internal Medicine, School of Medicine, Mashhad University of Medical Sciences, Mashhad, Iran.

Tel: +98.51.38022370, Fax:+98.51.38535980, Email: Akhavanrk@mums.ac.ir

Received: January 25, 2018, Accepted: May 08, 2018, Published: July 2018

iThenticate screening: May 08, 2018, English editing: May 17, 2018, Quality control: June 12, 2018

This article has been reviewed / commented by five experts

Funding / research project approval: 950153 (Mashhad University of Medical Sciences Research Council)

Ethics approval: IR.MUMS.REC.1395.379 (Mashhad University of Medical Sciences)

(C) 2018 The Authors. This is an open access article under the terms of the Creative Commons Attribution-NonCommercialNoDerivs License, which permits use and distribution in any medium, provided the original work is properly cited, the use is non-commercial and no modifications or adaptations are made. 
Trial registration: The trial was registered at the Iranian Registry of Clinical Trials (http://www.irct.ir) with the code of IRCT2016110630739N1.

Funding: This study was supported by funding (grant no.: 950153) from the Mashhad University of Medical Sciences Research Council, Mashhad, Iran.

Keywords: Gastroparesis, Diabetes mellitus, Pistacia atlantica, Persian medicine

\section{Introduction}

Gastroparesis is a digestive complaint described by delayed gastric emptying without mechanical obstruction (1). There are two major etiologies for gastroparesis including diabetes mellitus and idiopathic form. More than onethird of gastroparesis that can be seen in diabetic patients, is mainly prolonged and poorly controlled diabetes (2). The main symptoms are nausea, retching, vomiting, burping and belching, abdominal distention, early satiety, postprandial heaviness, and abdominal pain above the navel (3). Other complications are loss of appetite, malnutrition, poor quality of life, and impaired glycemic control due to incomplete delivery of nutrients and drugs to the small intestine for absorption (4). The high prevalence rate of diabetic gastroparesis (DGP) in the world is estimated at about 30 to $50 \%$ in type 1 and 2 diabetic patients. These manifestations show the importance of research in the management of this disease $(3,5)$. The pathogenesis of diabetic gastroparesis is incompletely recognized (6). Various etiologies such as uncontrolled blood sugar, autonomic neuropathy, vagal neuropathy and hormonal disorders play important roles in the pathogenesis (7). Prokinetic agents including dopamine antagonists and motilin agonists are widely used to treat diabetic gastroparesis $(8,9)$. These drugs have significant side effects such as inhibiting dopamine due to increased prolactin, gynecomastia, galactorrhea, dystonic reactions, and cardiac arrhythmias (10-13). Erythromycin increases antimicrobial resistance and changes the intestinal microbial flora (14). Due to insufficient satisfaction of current treatments and their side effects, the use of complementary and alternative medicine in this field seems essential (15). According to Persian medicine literature, the stomach is the main place for digestion that plays an important role in human health (16). Gastroparesis may occur due to excessive moisture and/or coldness in the stomach. One of the best herbal medicines that is frequently mentioned in stomach disorders in Persian medicine literature is Pistacia atlantica gum; different parts of $P$. atlantica have beneficial effects in gastrointestinal, liver, brain and kidney disorders (17-20). Recent studies demonstrate the wide pharmacological aspect from various parts of $P$. atlantica, such as antidiabetic, antihyperlipidemic, anti-inflammatory, antioxidant, and antimicrobial effects (21-23). The most effective antimicrobial agent isolated from the resin of Pistacia atlantica kurdica is related to triterpenes, 3-O-acetyl-3-epiisomasticadienolic acid (24). In vitro studies demonstrate its antimicrobial activity on Helicobacter pylori. The essential oil is one of the main components reported from its resin. The main chemical composition in essential oil is terpenoids with $\alpha$-pinene and $\beta$-pinene $(24,25)$. Considering the role of complementary medicine, the objective of this study was to assess the effects of Pistacia atlantica gum on diabetic gastroparesis symptoms. In addition, blood glucose, blood pressure and body mass index were evaluated.

\section{Material and Methods}

\subsection{Trial design}

To perform this study, we designed a randomized triple-blind, placebo-controlled clinical trial from November 2016 to May 2017.

\subsection{Participants}

The research population was selected from the diabetes clinic and gastrointestinal clinic of Imam Reza Hospital, (a general hospital affiliated to Mashhad University of Medical Sciences). This hospital is a major medical center in Mashhad, northeastern Iran. Patients with type 1 or 2 diabetes older than 18 years with primary clinical symptoms of digestive disorder referred to gastroenterologist and endocrine specialist to diagnose and evaluate the signs and symptoms of gastroparesis in order to rule out the mechanical obstruction and other gastroenterology disorders. Endoscopy was performed for all patients over the age of 55 and patients with risk factors such as unexplained weight loss, odynophagia, dysphagia, family history for gastrointestinal cancer.

\subsection{Selection criteria}

The inclusion criteria in this study was patients with a history of five years diabetes (type 1 or 2), older than 18 years, and with clinical symptoms of gastroparesis for more than six months determined by the Gastroparesis cardinal symptom index (GCSI). Gastroparesis was diagnosed clinically by physical examination and ruled out mechanical obstruction with upper endoscopy in diabetic patients, and gastric emptying tests did not perform for eligibility (26). The exclusion criteria were: 1) organic disorders in the upper endoscopy report in patients with risk factors such as unexplained weight loss, odynophagia, dysphagia, family history for gastrointestinal cancer, 2) 
evidence of mechanical obstruction of the stomach or bowel, 3) history of gastrectomy, gastric bypass, gastroplasty, pyloroplasty and vagotomy, 4) classical eating disorders (anorexia nervosa, bulimia), 5) patients with heart failure, kidney failure, hepatitis or liver failure, 6) uncontrolled thyroid disorders, 7) endoscopic botulinum toxin injection in the pylorus in the past 6 months, 8) patients who have been treated with electrical stimulation of the stomach, 9) consumers of medicines that induce delayed gastric emptying such as acarbose, miglitol, exenatide, benzodiazepines, calcium channel blockers, narcotics, alpha-2 adrenergic receptor agonists such as clonidine, tricyclic antidepressants, dopamine agonists, cholinergic muscarinic receptor antagonists, octreotide, phenothiazines, cyclosporine, 10) patients with dry mouth and dry tongue, 11) history of allergy to Pistacia atlantica, 12) Pregnancy and lactation, 13) patient's unwillingness to continue the project, 14) incidence of possible side effects. The study flowchart is illustrated in Figure 1.

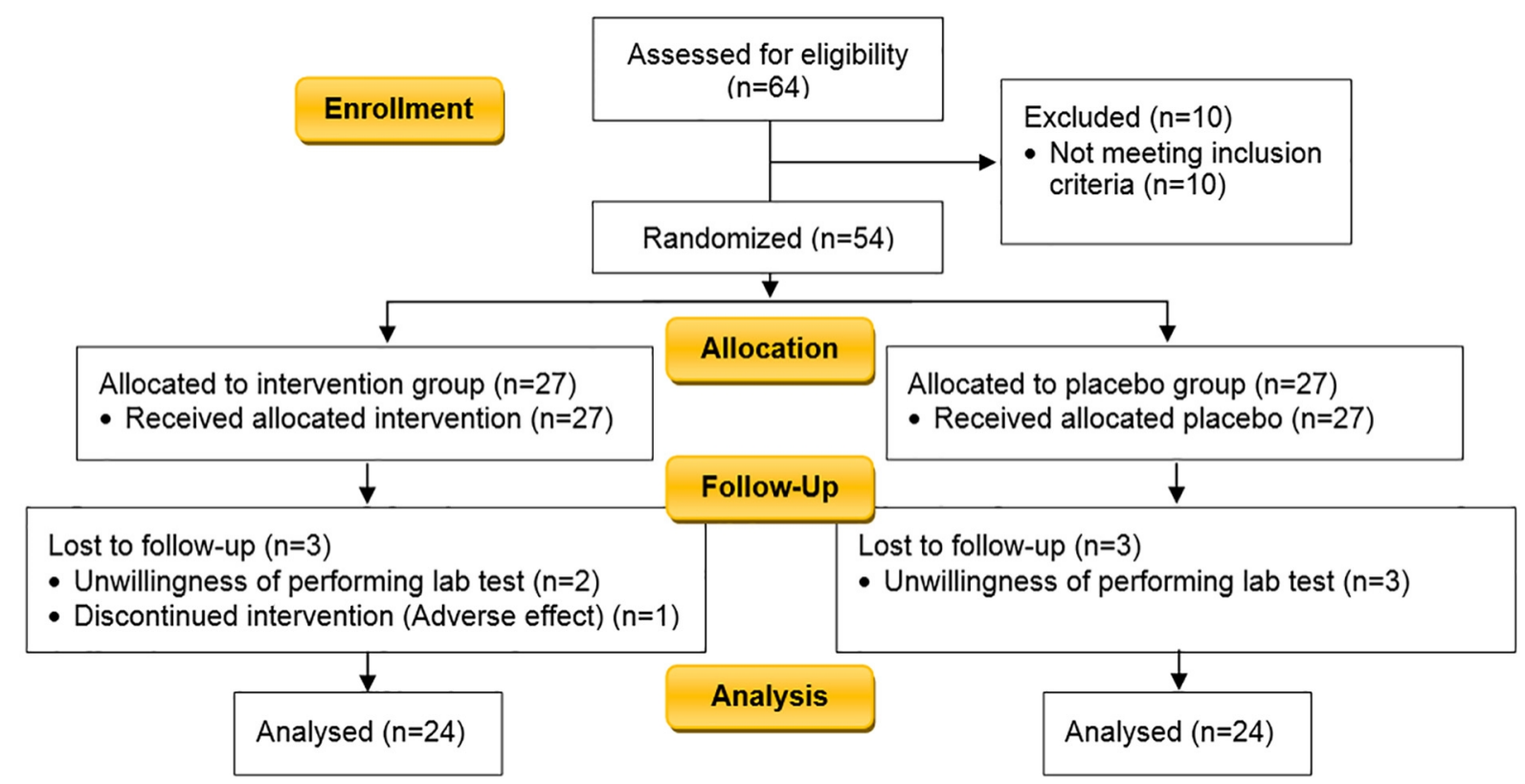

Figure 1. CONSORT 2010 Flow Diagram of the study

\subsection{Interventions}

\subsubsection{Interventions}

In the present study, 64 diabetic patients with suspected gastroparesis symptoms were evaluated at the clinics, and 10 patients were excluded because of disorders reported by endoscopy and their drug history (consumer of medicines that induce delayed gastric emptying). Fifty-four patients (14.6\% diabetes type 1 and $85.4 \%$ diabetes type 2) were divided by balanced block randomization method into two groups of intervention (2 gram Pistacia atlantica chewing gum, two times a day) and placebo (sugar free chewing contained industrial plastic polymers, two times a day) for one month. Both groups received current dietary advice for DGP (mmultiple meals with low-volume and light food and avoiding thick or condense food). Type of diabetes and their medications are not important in this study but $\mathrm{HbAlc}$ level was matched in both groups.

\subsubsection{Measurement of gastroparesis symptom severity}

The severity of symptoms at commencement and 1,2,3,4 weeks and one month after the end of intervention was measured with Gastroparesis cardinal symptom index (GCSI) standard questionnaire. Validity and reliability of this English questionnaire were evaluated. The questionnaire includes 3 groups of symptoms consisting of nausea/vomiting, postprandial fullness/early satiety, and bloating which is designed in the form of 9 questions based on the Likert scale (none, very mild, mild, moderate, severe and very severe) (27-30).

\subsubsection{Biochemical analysis}

Biochemical blood tests were performed at the beginning and end of the study (week 4). These measurements include: Complete blood count (CBC), Glycated hemoglobin (HbA1c), Fasting blood sugar (FBS). The aim of these measurements is to assess the glycemic profile changes. Improvement of gastroparesis symptoms has a great effect on carbohydrate absorption through the release of gut peptides (6); Gastroparesis can also disturb absorption of oral hypoglycemic drugs (31). 
http://www.ephysician.ir

2.4.4. Determination of Pistacia atlantica kurdica gum ingredients with Gas chromatography/mass selective detector (GC-MSD)

Pistacia atlantica resin which is used in this study has been harvested from the state of Kordestan in Iran in 2016 and standardized by gas chromatography/mass selective detector. GC-MSD is a useful technique for the analysis of terpenoids, especially mono- and sesquiterpenes, in various resins (32). The GC-MSD analysis of the oleo-gumresin of Pistacia atlantica var. kurdica led to identifying 38 compounds (Table 1). The comparison of the retention times and mass selective detection data of these 38 compounds with reference compounds, library matching, and fragmentation patterns in the literature showed the main components were $\alpha$-pinene $(82.64 \%), \beta$-pinene $(3.04 \%)$, verbenol $(1.43 \%)$, $\alpha$-terpinolen $(1.25 \%)$, L-limonene (1.03\%), Benzenemethanol, and $\alpha, \alpha$-4-trimethyl (1.02\%). These results are almost similar to pervious GC-MS research about Pistacia atlantica gum. The resin in the present study was standard with $\alpha$-pinene and $\beta$-pinene. Total components and their retention time are shown in Table 1 and Figures 2 and 3.

Table 1. Components of the essential oil of the resin of Pistacia atlantica var. kordica Analyzed by GC-MSD

\begin{tabular}{|l|l|l|}
\hline Component & Retention time (min) & Area (\%) \\
\hline 1-propoxybutane & 10.0 & 0.13 \\
\hline 1-ethoxypentane & 10.32 & 0.14 \\
\hline 1,3,5-trioxepane & 10.86 & 0.19 \\
\hline Ethyl cyclohexane & 11.81 & 0.11 \\
\hline$\alpha$-pinene or 3-octen-5-yne-2,7-dimethyl-(z) & 15.39 & 82.64 \\
\hline Camphene & 15.95 & 0.82 \\
\hline 1-isoproyl-4-methylenebicyclo[3.1.0.]hex-2-ene & 16.05 & 0.32 \\
\hline (+)-sabinene & 16.68 & 0.4 \\
\hline$\beta$-pinene & 16.92 & 3.04 \\
\hline (-)- $\beta$-pinene & 17.12 & 0.11 \\
\hline Terpinolene & 17.57 & 0.07 \\
\hline 6,6-dimethyl-2-methylenebicyclo[3.1.1]heptane & 17.91 & 0.63 \\
\hline$\alpha$-terpinene & 18.19 & 0.05 \\
\hline p-cymene & 18.46 & 0.35 \\
\hline L-limonene & 18.61 & 1.03 \\
\hline Eucalyptol & 18.77 & 0.27 \\
\hline Gamma- terpinene & 19.56 & 0.04 \\
\hline Cis, $\beta$-terpineol & 20.03 & 0.07 \\
\hline$\alpha$-terpinolen & 20.47 & 1.25 \\
\hline 5-7-dodecadiyn-1-12-diol & 20.61 & 0.29 \\
\hline$\beta$-linalool & 20.84 & 0.15 \\
\hline$\alpha$-pinene epoxide & 21.05 & 0.14 \\
\hline Cis-verbenol & 21.40 & 0.99 \\
\hline$\alpha$-campholenal & 21.87 & 0.15 \\
\hline Cis-3-oxabicyclo[4-3.0]non-8-en-2-one & 22.34 & 0.78 \\
\hline Pino carveol & 22.43 & 0.82 \\
\hline (+)-verbenol & 22.51 & 1.43 \\
\hline 1-2-camphanol & 22.41 & 0.13 \\
\hline 2-6-octadienal,3,7-dimethyl & 23.50 & 0.1 \\
\hline Benzenemethanol, $\alpha, \alpha-4-$-trimethyl & 23.75 & 1.02 \\
\hline$\alpha$ - terpineol & 24.02 & 0.5 \\
\hline -)-myrtenol & 24.08 & 0.23 \\
\hline 1-verbenone & 24.48 & 0.35 \\
\hline Cis-carveol & 24.69 & 0.3 \\
\hline Cis-verbenol & 26.50 & 0.07 \\
\hline Bornyl acetate & 26.59 & 0.58 \\
\hline Cis-linalool oxide & 27.57 & 0.18 \\
\hline Exo-2-hydroxy cineole acetate & 28.05 & 0.12 \\
\hline & & \\
\hline
\end{tabular}




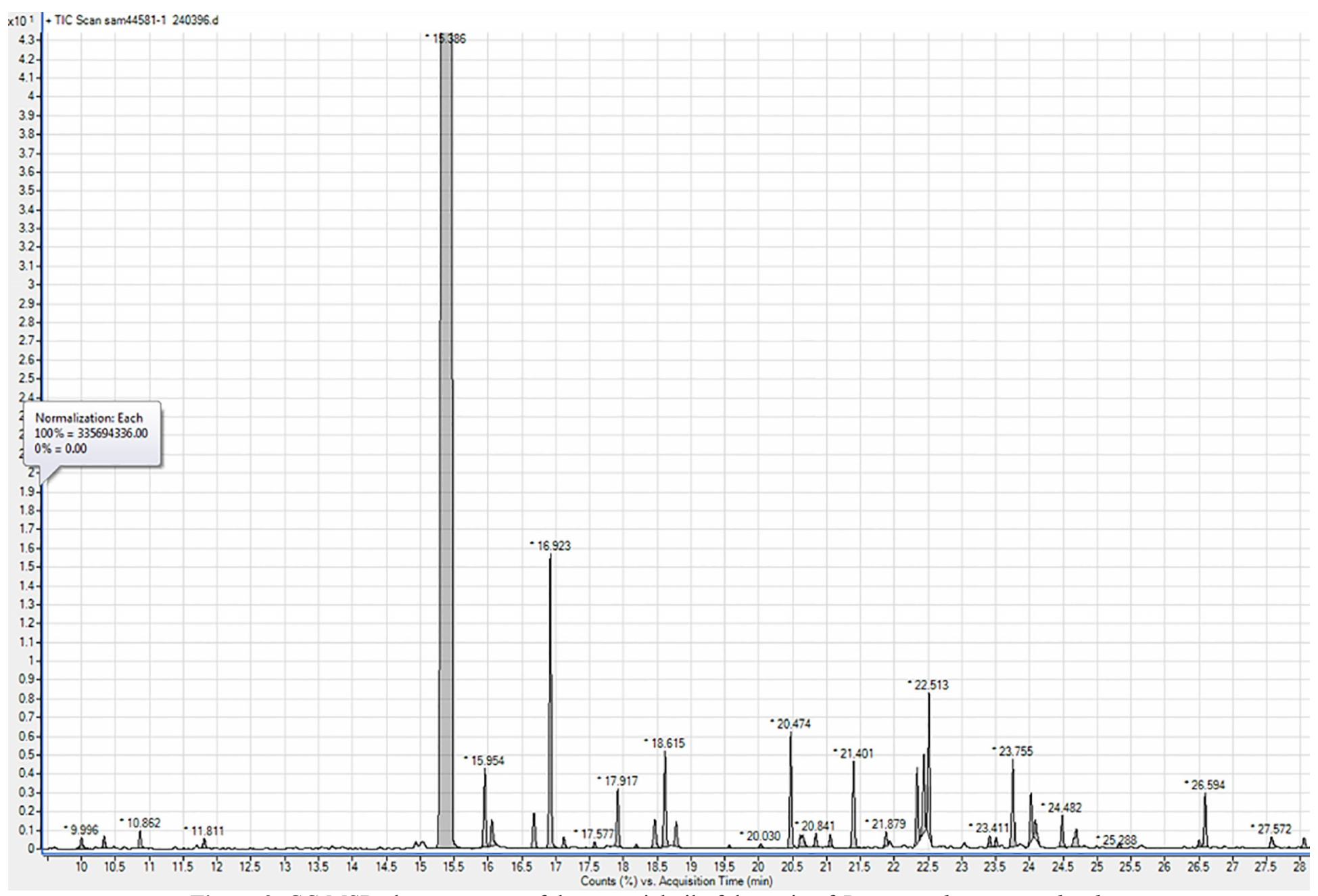

Figure 2. GC-MSD chromatogram of the essential oil of the resin of Pistacia atlantica var. kurdica<smiles>CC1=CCC2CC1C(C)(C)C2</smiles><smiles>CC1(C)C2CCCC1C2</smiles>

\section{$\alpha$-Pinene}

\section{$\beta$-Pinene}

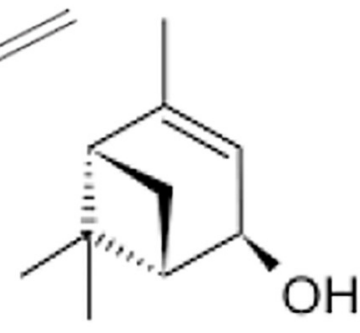<smiles>CC1=CCC(=C(C)C)CC1</smiles><smiles>C=C(C)C1CC=C(C)CC1</smiles>

Figure 3. Main components isolated from resin of Pistacia atlantica var. kordi

\subsection{Outcomes}

Primary outcomes were severity of gastroparesis symptoms that were determined with GCSI questionnaire. Secondary outcomes included assessment of FBS, HbA1c, blood pressure, Body mass index and adverse effects.

\subsection{Sample size}

There was no similar study for the sample size and we considered medium effect size $(\Delta=0.4$, power $=80 \%$ and confidence interval $=95 \%$ ) for calculating sample size. Considering $10 \%$ drop-out during the study time, the sample size was calculated as 27 subjects per group. 


\subsection{Randomization and blinding}

Patients were divided into two groups which included Pistacia atlantica and placebo, by balanced block randomization method. Randomized sequence generation was considered as block size of four variables. This clinical trial was a triple-blinded study of which patients and an investigator who performed the clinical assessments and statistical analyzer were blinded.

\subsection{Statistical methods}

SPSS software version 16 (Statistical package for the Social Sciences, SPSS Inc., Chicago, IL, USA) was used to analyze the data, and the normality of distribution was assessed using Kolmogorov-Smirnov test. Independentsamples t-test, Paired-samples t-test, Mann-Whitney U test, and Wilcoxon signed-rank test were used to assess the effect of treatment on quantitative and qualitative variables between group differences and within group changes. To control confounding variables such as sex and age by statistical analysis, GEE (Generalized Estimating Equation) model was used.

\subsection{Research ethics}

The study was approved by the Medical Ethics Committee of Mashhad University of Medical Sciences with the code of IR.MUMS.REC.1395.379 and registered in the Iranian registry of clinical trials with the ID: IRCT2016110630739N1. The aim and object of the study were explained for the patients. Informed consent was obtained from all participants in their native language (Persian) prior to the study. All patient information was kept confidential. We were committed to allow the participants to leave the study, anytime they wanted.

\section{Results}

Fifty-four patients were enrolled in the study but 6 patients did not return for follow-up (Figure 1). The remaining 48 patients completed the treatment. Their age range was 30-73 years with the average of $51.19( \pm 10.96)$ years. The groups of patients randomly allocated to receive Pistacia atlantica var. Kurdica gum (PAK) or placebo, had similar characteristics in most variables at baseline (Table 2). Dependent variables including body mass index, systolic and diastolic blood pressure, Glycated hemoglobin (HbA1c), and Fasting blood sugar (FBS) were assessed at baseline and immediately after treatment period ( 1 month) (Table 3$)$. Systolic blood pressure $(\mathrm{p}=0.006)$, BMI $(\mathrm{p}=0.018)$, and $\mathrm{HbA1c}(\mathrm{p}=0.038)$ significantly decreased in the PAK group after the treatment. Postprandial fullness/early satiety $(p=0.04)$, bloating $(p<0.0001)$, GCSI scores $(p=0.001)$, stomach fullness $(p<0.0001)$, feeling excessively full after meals ( $\mathrm{p}=0.011$ ), bloating (feeling like you need to loosen your clothes $(\mathrm{p}<0.0001)$, stomach or belly visibly larger $(\mathrm{p}<0.0001)$ significantly decreased in the PAK group versus placebo after the treatment in follow up patients (Table $4,5)$. Some of the symptoms' improvement was related to male sex; Postprandial fullness/early satiety ( $\mathrm{p}=0.016)$, loss of appetite $(\mathrm{p}=0.004)$, nausea $(\mathrm{p}=0.007)$, not able to finish a normal-sized meal $(\mathrm{p}=0.002)$, and GCSI score $(\mathrm{p}=0.01)$ significantly decreased in male sex. Retching $(\mathrm{p}=0.003)$ and Nausea /vomiting $(\mathrm{p}=0.034)$ significantly decreased in $\mathrm{HbAl} c \leq 7$ group. Reducing the severity of bloating was significant in the group that observed the correct diet $(\mathrm{p}=0.026)$. GCSI scores was measured one month after the end of intervention. GCSI score mean change from baseline to week 8 for both groups is shown in Figure 4. Adverse effects assessed in this study; one patient in the PAK group did not complete the treatment Course owing to gastric upset induced by PAK odor. Another patient in the placebo group did not complete the treatment period because of toothache and could not chew the placebo.

Table 2. Baseline information and symptoms change of the diabetic gastroparesis patients

\begin{tabular}{|l|l|l|l|l|}
\hline \multirow{2}{*}{ Variable } & Groups & \multirow{2}{*}{ p-value } \\
\cline { 2 - 4 } & PAK & Placebo & \\
\hline Age (years); Mean \pm SD & $53.29 \pm 11.71$ & $49.08 \pm 9.95$ & $0.187^{\mathrm{a}}$ \\
\hline Duration of diabetes (years); Mean \pm SD & $10.45 \pm 5.19$ & $10.54 \pm 6.74$ & $0.962^{\mathrm{a}}$ \\
\hline Gastroparesis duration (months); Mean \pm SD & $30.96 \pm 30.82$ & $41.71 \pm 45.48$ & $0.343^{\mathrm{a}}$ \\
\hline \multirow{2}{*}{ Sex, n (\%) } & Male & $4(16.7)$ & $4(16.7)$ & \multirow{2}{*}{$1.000^{\mathrm{b}}$} \\
\cline { 2 - 4 } & Female & $20(83.3)$ & $20(83.3)$ & \\
\hline \multirow{2}{*}{ Type of diabetes, $\mathrm{n}(\%)$} & Type 1 & $3(12.5)$ & $4(16.7)$ & \multirow{2}{*}{$0.683^{\mathrm{b}}$} \\
\cline { 2 - 3 } & Type 2 & $21(87.5)$ & $20(83.3)$ & \\
\hline
\end{tabular}

a: Independent-samples t-test, b: Chi-Square test 


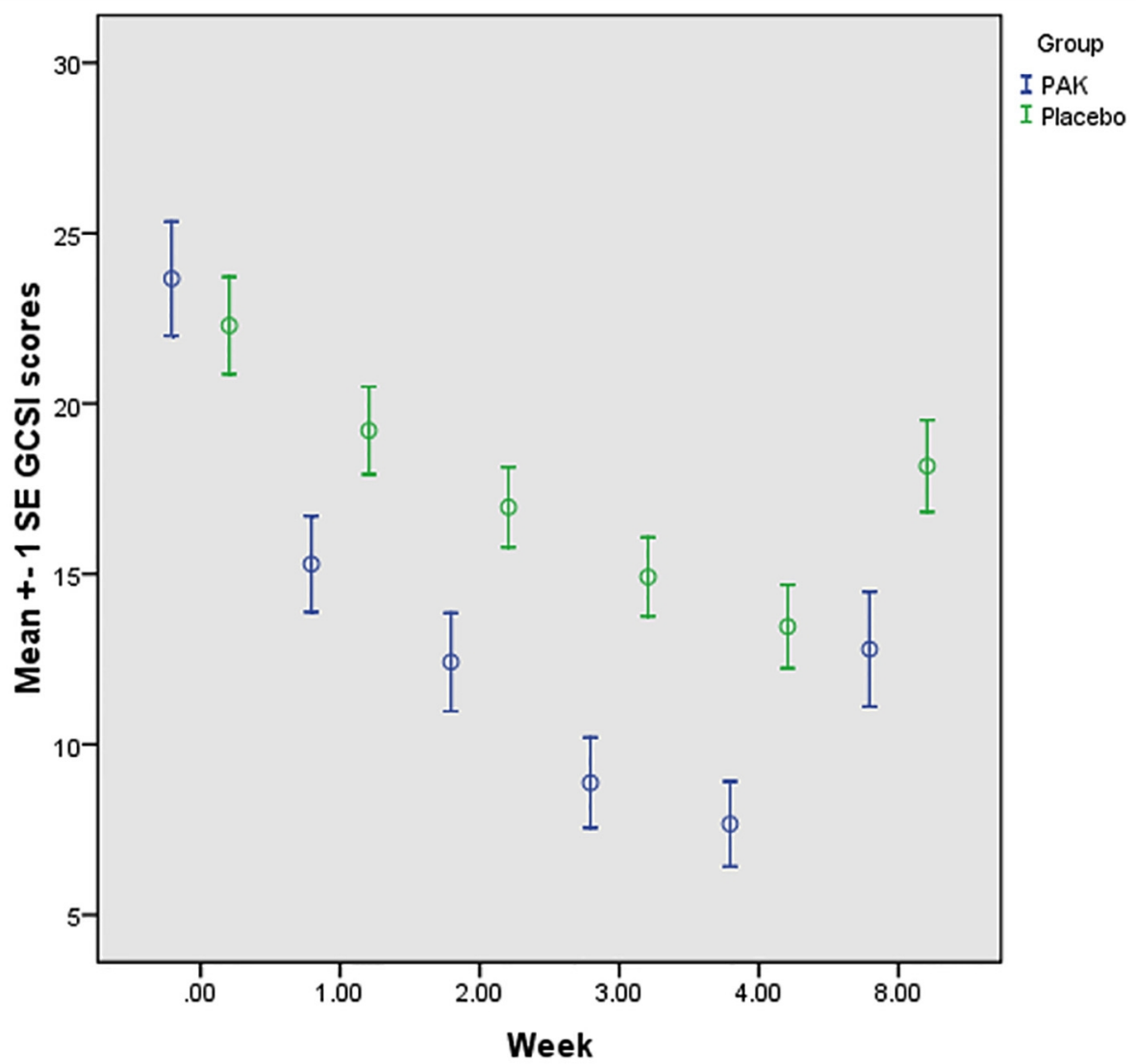

Figure 4. GCSI score mean change from baseline for PAK and placebo groups.

Table 3. Outcome data in two groups, baseline and four weeks after the intervention

\begin{tabular}{|c|c|c|c|c|c|c|}
\hline \multirow[t]{2}{*}{ Variable } & \multicolumn{2}{|c|}{ PAK; Mean \pm SD } & \multirow{2}{*}{$\begin{array}{l}\text { p-value } \\
\text { (PAK) }\end{array}$} & \multicolumn{2}{|c|}{ Placebo; Mean \pm SD } & \multirow{2}{*}{$\begin{array}{l}\text { p-value } \\
\text { (Placebo) }\end{array}$} \\
\hline & Baseline & Week 4 & & Baseline & Week 4 & \\
\hline Systolic blood pressure (mmHg) & $122.29 \pm 18.47$ & $116.04 \pm 14.29$ & $0.014^{\mathrm{a}}$ & $117.92 \pm 14.66$ & $117.50 \pm 13.59$ & $0.831^{\mathrm{a}}$ \\
\hline Diastolic blood pressure $(\mathrm{mmHg})$ & $80.83 \pm 7.17$ & $78.54 \pm 4.99$ & $0.077^{\mathrm{b}}$ & $77.29 \pm 6.75$ & $77.50 \pm 5.31$ & $0.785^{\mathrm{b}}$ \\
\hline Body mass index $\left(\mathrm{Kg} \mathrm{mg}^{-1}\right)$ & $31.76 \pm 5.03$ & $31.27 \pm 4.66$ & $0.018^{\mathrm{a}}$ & $32.66 \pm 7.85$ & $32.53 \pm 7.78$ & $0.263^{\mathrm{a}}$ \\
\hline FBS $\left(\mathrm{mg} \mathrm{dl}^{-1}\right)$ & $175.17 \pm 68.10$ & $163.79 \pm 57.84$ & $0.410^{\mathrm{a}}$ & $176.33 \pm 58.06$ & $166.33 \pm 72.98$ & $0.482^{\mathrm{a}}$ \\
\hline HbA1c (\%) & $8.47 \pm 2.18$ & $7.89 \pm 1.79$ & $0.038^{\mathrm{a}}$ & $8.42 \pm 1.98$ & $8.47 \pm 2.12$ & $0.798^{\mathrm{a}}$ \\
\hline
\end{tabular}

A: Paired-sample t-test, b: Wilcoxon signed-rank test

Table 4. Mean scores change of symptoms from baseline to week 4 for PAK and placebo groups

\begin{tabular}{|l|l|l|l|l|}
\hline \multirow{2}{*}{ Variable } & PAK & \multicolumn{3}{l|}{ Placebo } \\
\cline { 2 - 5 } & Baseline & Week 4 & Baseline & Week 4 \\
\hline Nausea and vomiting & $4.75 \pm 4.90$ & $1.12 \pm 1.70$ & $3.62 \pm 3.18$ & $1.71 \pm 2.07$ \\
\hline Nausea & $2.25 \pm 2.00$ & $0.62 \pm 0.92$ & $2.17 \pm 1.92$ & $1.04 \pm 1.23$ \\
\hline Retching & $1.46 \pm 1.86$ & $0.33 \pm 0.76$ & $0.96 \pm 1.30$ & $0.54 \pm 0.88$ \\
\hline Vomiting & $1.04 \pm 1.80$ & $0.08 \pm 0.28$ & $0.50 \pm 0.78$ & $0.12 \pm 0.33$ \\
\hline Postprandial fullness/early satiety & $11.00 \pm 5.27$ & $3.54 \pm 3.71$ & $9.79 \pm 4.35$ & $5.92 \pm 2.53$ \\
\hline Stomach fullness & $4.08 \pm 1.53$ & $1.04 \pm 0.99$ & $3.96 \pm 1.39$ & $2.29 \pm 1.23$ \\
\hline Not able to finish a normal-sized meal & $1.83 \pm 2.14$ & $0.54 \pm 1.17$ & $1.12 \pm 1.87$ & $0.62 \pm 1.17$ \\
\hline Feeling excessively full after meals & $3.75 \pm 1.87$ & $1.08 \pm 1.28$ & $4.00 \pm 1.38$ & $2.50 \pm 1.28$ \\
\hline Loss of appetite & $1.33 \pm 1.92$ & $0.62 \pm 1.49$ & $0.70 \pm 1.32$ & $0.42 \pm 0.88$ \\
\hline Bloating & $8.33 \pm 2.23$ & $3.00 \pm 2.41$ & $8.88 \pm 2.62$ & $5.92 \pm 2.53$ \\
\hline Bloating (feeling need to loosen your clothes) & $4.17 \pm 1.16$ & $1.33 \pm 1.09$ & $4.42 \pm 1.31$ & $2.92 \pm 1.24$ \\
\hline Stomach or belly visibly larger & $4.17 \pm 1.12$ & $1.29 \pm 1.04$ & $4.46 \pm 1.31$ & $3.00 \pm 1.31$ \\
\hline
\end{tabular}

Data are presented as Mean \pm SD 
Table 5. Adjusted treatment effect on gastroparesis symptoms from week 0 to week 4

\begin{tabular}{|l|l|l|l|}
\hline Parameter (PAK vs. placebo) & Regression coefficients ( $(\boldsymbol{\beta})$ & Std. Error & P-value \\
\hline Nausea and vomiting & -0.672 & 0.938 & 0.474 \\
\hline Nausea & -0.684 & 0.461 & 0.138 \\
\hline Retching & -0.141 & 0.262 & 0.592 \\
\hline Vomiting & 0.062 & 0.158 & 0.698 \\
\hline Postprandial fullness/early satiety & -2.016 & 0.980 & 0.040 \\
\hline Stomach fullness & -1.09 & 0.306 & $<0.0001$ \\
\hline Not able to finish a normal-sized meal & 0.233 & 0.473 & 0.623 \\
\hline Feeling excessively full after meals & -1.148 & 0.449 & 0.011 \\
\hline Loss of appetite & 0.285 & 0.350 & 0.416 \\
\hline Bloating & -2.447 & 0.593 & $<0.0001$ \\
\hline Bloating (feeling like you need to loosen your clothes) & -1.228 & 0.290 & $<0.0001$ \\
\hline Stomach or belly visibly larger & -1.341 & 0.293 & $<0.0001$ \\
\hline GCSI scores & -5.091 & 1.494 & 0.001 \\
\hline
\end{tabular}

* Generalized Estimating Equation (GEE) model

\section{Discussion}

This study is the first to design the efficacy of PAK in the treatment of diabetic gastroparesis symptoms. In this study, more than $50 \%$ of patients were in age group $>50$ years and mean of duration of diabetes was 10 years; this showed gastroparesis is directly related to diabetic time. Distribution of sex was not normal. This can be interpreted that women have more common risk factors than men, factors such as low physical activity, obesity, etc. More than $80 \%$ patients were type 2 diabetes mellitus and mean of BMI was $31 \mathrm{~kg} / \mathrm{m} 2$. It can probably be considered that obesity is the risk factor of diabetic gastroparesis. According to research findings, all gastroparesis symptoms including nausea and vomiting, postprandial fullness/early satiety, and bloating were significantly declined in each group during the study $(\mathrm{p}<0.0001)$. It can be justified by the important role of dietary advice in the treatment of both groups. Although there is not a study similar to our clinical trial, Eva A. Olausson conducted a study for assessment dietary advices in diabetic gastroparesis, and found that a small portion diet improves gastroparesis symptoms (33). Postprandial fullness/early satiety, bloating and GCSI scores significantly decreased in the PAK group vs. placebo after the treatment. Also, HbAlc significantly decreased in the PAK group, but there is no significant difference between groups. Although, we did not expect to observe a treatment effect of PAK on HbAlc due to the short duration of the treatment periods (the present intervention lasted only 4 weeks). This can be interpreted improvement of gastroparesis symptoms has a main effect on carbohydrate absorption and through the release of gut peptides and enhancement absorption of oral hypoglycemic drugs $(6,31)$. One study was performed regarding the effect of cinnamon on delay gastric emptying and postprandial glucose in healthy volunteers, and found both of mentioned variables were reduced in the cinnamon group. Similar studies include the effects of Chios mastic gum (from Anacardiacea family herb) on cholesterol and glucose levels of healthy subjects, and demonstrate significant lowering effects on total cholesterol and glucose levels (34). It seems that using PAK for a longer period can lead to better results. Further study should be assessed to investigate these effects.

In pathogenesis of gastroparesis, pyloric contraction due to neuropathy and loss of expression of neuronal nitric oxide is important. The mentioned mechanism may be related to immune disturbance or reactive oxygen species (35). According to Persian medicine, the main mechanism in gastroparesis is "phlegmatic temperament". Based on Persian medicine, oleoresin of PAK is stomach and nerve tonic and has proper effect on gastrointestinal disorder especially stomach diseases and neurological disease $(16,20)$. These properties cover the main therapeutic goals in neuropathy and gastrointestinal disorder in diabetic patients. Essential oil of PAK stimulates gastric motility by its ingredients that are $\alpha$-pinene, $\beta$-pinene, verbenol, $\alpha$-terpinolen and limonene. These components may increase peristaltic contraction in the fundus and antrum with strengthening of the gastric smooth muscles and nerves (36, 37). On the other hand, it may decrease pyloric contraction due to improved NOs activity (NO-cGMP mediated pathway) (38). Recent studies showed $P$. atlantica has anti-inflammatory, antioxidant, antidiabetic, and antihyperlipidemic activities (22, 39-41); Therefore PAK can reduce oxidative and inflammatory processes in DGP.

\section{Study limitations}

Our study had positive points such as considering placebo and blinding method designs. The limitations of the study were: 1) Short study period intervention for one month, 2) not evaluating HbAlc after tree month, 3) not performing scintigraphy for measurement of gastric emptying rates. 


\section{Conclusions}

The efficacy of PAK of diabetic gastroparesis symptoms was evidenced in this work. This study exhibited significant improvement in diabetic gastroparesis symptoms. More investigation should be done regarding its safety. Comparison with other drug protocols, and longer period intervention is recommended.

\section{Acknowledgments:}

This article is based on a $\mathrm{PhD}$ postgraduate thesis of Dr. Fatemeh Mahjoub entitled "The effect of Pistacia atlantica Kurdica gum on diabetic gastroparesis symptoms". The authors appreciate all the staff members and nurses who worked in the diabetes clinic of Imam Reza Hospital.

\section{Funding:}

This study was supported by funding (grant no 950153) from the Mashhad University of Medical Sciences Research Council, Mashhad, Iran.

\section{Trial registration:}

The trial was registered at the Iranian Registry of Clinical Trials (http://www.irct.ir) with the code of IRCT2016110630739N1.

\section{Conflict of Interest:}

There is no conflict of interest to be declared.

\section{Authors' contributions:}

Mahjoub F. wrote the manuscript; Mahjoub F. \& Akhavan Rezayat K. \& Salari R performed the research, Yousefi M. \& Mohebbi M. designed the research study, Akhavan Rezayat K. \& Salari R coauthored the manuscript; Saki A. analyzed the data. All authors approved the final version of the manuscript.

\section{References:}

1) Kasper DL, Fauci AS, Hauser S, Longo D, Jameson JL, Loscalzo J. Harrison's Principles of Internal Medicine 19/E (Vol 4): McGraw-Hill Education; 2015.

2) Soykan I, Sivri B, Sarosiek I, Kiernan B, Mccallum RW. Demography, clinical characteristics, psychological and abuse profiles, treatment, and long-term follow-up of patients with gastroparesis. Dig Dis Sci. 1998; 43(11): 2398-404. doi: 10.1023/A:1026665728213.

3) Camilleri M, Bharucha AE, Farrugia G. Epidemiology, mechanisms, and management of diabetic gastroparesis. Clin Gastroenterol Hepatol. 2011; 9(1): 5-12. doi: 10.1016/j.cgh.2010.09.022.

4) Shin AS, Camilleri M. Diagnostic assessment of diabetic gastroparesis. Diabetes. 2013; 62(8): 2667-73. doi: $10.2337 / \mathrm{db} 12-1706$.

5) Maleki D, Locke GR, Camilleri M, Zinsmeister AR, Yawn BP, Leibson C, et al. Gastrointestinal tract symptoms among persons with diabetes mellitus in the community. Arch Intern Med. 2000; 160(18): 280816. doi: 10.1001/archinte.160.18.2808.

6) Bharucha AE, Batey-Schaefer B, Cleary PA, Murray JA, Cowie C, Lorenzi G, et al. Delayed gastric emptying is associated with early and long-term hyperglycemia in type 1 diabetes mellitus. Gastroenterology. 2015; 149(2): 330-9. doi: 10.1053/j.gastro.2015.05.007.

7) Lee A, Kuo B. Metoclopramide in the treatment of diabetic gastroparesis. Expert Rev Endocrinol Metab. 2010; 5(5): 653-62. doi: 10.1586/eem.10.41. PMID: 21278804, PMCID: PMC3027056.

8) McCarty TR, Rustagi T. Endoscopic treatment of gastroparesis. World J Gastroenterol. 2015; 21(22): 68429. doi: 10.3748/wjg.v21.i22.6842. PMID: 26078560, PMCID: PMC4462724.

9) Janssens J, Peeters T, Vantrappen G, Tack J, Urbain J, De Roo M, et al. Improvement of gastric emptying in diabetic gastroparesis by erythromycin: preliminary studies. N Engl J Med. 1990; 322(15): 1028-31. doi: 10.1056/NEJM199004123221502. PMID: 2320062.

10) Casey DE. Metoclopramide side effects. Ann Intern Med. 1983; 98(5_Part_1): 673-4. doi: 10.7326/00034819-98-5-673_3.

11) Grimes J, Hassan M, Preston D. Adverse neurologic effects of metoclopramide. Can Med Assoc J. 1982; 126(1): 23-5. PMID: 7059869, PMCID: PMC1862808.

12) Bateman D, Rawlins M, Simpson JM. Extrapyramidal reactions with metoclopramide. BMJ. 1985; 291(6500): 930-2. doi: 10.1136/bmj.291.6500.930. 
13) Ponti D, Nucci D. Review article: cardiac adverse effects of gastrointestinal prokinetics. Aliment Pharmacol Ther. 1999; 13(12): 1585-91. PMID: 10594392.

14) McCallum R, Cynshi O. Clinical trial: effect of mitemcinal (a motilin agonist) on gastric emptying in patients with gastroparesis - a randomized, multicentre, placebo - controlled study. Aliment Pharmacol Ther. 2007; 26(8): 1121-30. doi: 10.1111/j.1365-2036.2007.03461.x.

15) Pang B, Zhou Q, Li JL, Zhao LH, Tong XL. Treatment of refractory diabetic gastroparesis: Western medicine and traditional Chinese medicine therapies. World J Gastroenterol. 2014; 20(21): 6504-14. doi: 10.3748/wjg.v20.i21.6504. PMID: 24914371, PMCID: PMC4047335.

16) Avicenna. Al-Qanun fi al-Tibb (The Canon of Medicine). Beirut: Alamy Le- Al-Matbooat institute; 2012.

17) Borhani M, Khoshzaban Z, Jodeiri B, Naseri M, Kamlinejad M, Faghihzade S. Comparison between used herbs for treatment of gastroesophageal reflux disease [GERD] in Iranian Traditional of Medicine. Adv Environ Biol. 2014: 773-82.

18) Aghili MH. Makhzan al Advie. Tehran: Tehran University of Medical Sciences; 2009.

19) AzamKhan M. Eksir Azam. The Institute for Medical History Islamic and Complementary Medicine. Tehran : Tehran University of Medical Sciences; 2004.

20) Bozorgi M, Memariani Z, Mobli M, Salehi Surmaghi MH, Shams-Ardekani MR, Rahimi R. Five Pistacia species (P. vera, P. atlantica, P. terebinthus, P. khinjuk, and P. lentiscus): a review of their traditional uses, phytochemistry, and pharmacology. Sci World J. 2013; 2013. doi: 10.1155/2013/219815.

21) Ghalem B, Benali M. Bactericidal activity of Pistacia atlantica. Desf mastic gum against certain pathogens. Afr J Plant Sci. 2009; 3(1): 013-5.

22) Minaiyan M, Karimi F, Ghannadi A. Anti-inflammatory effect of Pistacia atlantica subsp. kurdica volatile oil and gum on acetic acid-induced acute colitis in rat. RJP. 2015; 2(2): 1-12.

23) Ghalem B, Mohamed B. Essential oil from gum of Pistacia atlantica Desf: screening of antimicrobial activity. Afr J Pharm Pharmacol. 2009; 3(3): 87-91.

24) Sharifi MS, Hazell SL. Isolation, analysis and antimicrobial activity of the acidic fractions of Mastic, Kurdica, Mutica and Cabolica gums from genus Pistacia. Glob J Health Sci. 2012; 4(1): 217. doi: 10.5539/gjhs.v4n1p217.

25) Barrero A, Herrador M, Arteaga J, Akssira M, Mellouki F, Belgarrabe A, et al. Chemical composition of the essential oils of Pistacia atlantica Desf. J Essent Oil Res. 2005; 17(1): 52-4. doi: 10.1080/10412905.2005.9698828.

26) Parkman H, Carlson M, Gonyer D. Metoclopramide nasal spray is effective in symptoms of gastroparesis in diabetics compared to conventional oral tablet. J Neurogastroenterol Motil. 2014; 26(4): 521-8. doi: 10.1111/nmo.12296.

27) Revicki D, Rentz A, Dubois D, Kahrilas P, Stanghellini V, Talley N, et al. Development and validation of a patient - assessed gastroparesis symptom severity measure: the Gastroparesis Cardinal Symptom Index. Aliment Pharmacol Ther. 2003; 18(1): 141-50. doi: 10.1046/j.1365-2036.2003.01612.x.

28) Revicki DA, Rentz AM, Dubois D, Kahrilas P, Stanghellini V, Talley NJ, et al. Gastroparesis Cardinal Symptom Index (GCSI): development and validation of a patient reported assessment of severity of gastroparesis symptoms. Qual Life Res. 2004; 13(4): 833-44. doi: 10.1023/B:QURE.0000021689.86296.e4.

29) Revicki D, Camilleri M, Kuo B, Norton N, Murray L, Palsgrove A, et al. Development and content validity of a gastroparesis cardinal symptom index daily diary. Aliment Pharmacol Ther. 2009; 30(6): 670-80. doi: 10.1111/j.1365-2036.2009.04078.x.

30) Revicki D, Camilleri M, Kuo B, Szarka L, McCormack J, Parkman H. Evaluating symptom outcomes in gastroparesis clinical trials: validity and responsiveness of the Gastroparesis Cardinal Symptom Index Daily Diary (GCSI - DD). J Neurogastroenterol Motil. 2012; 24(5): 456-63. doi: 10.1111/j.13652982.2012.01879.x.

31) Groop L, Defronzo R, Luzi L, Melander A. Hyperglycaemia and absorption of sulphonylurea drugs. Lancet. 1989; 334(8655): 129-30. doi: 10.1016/S0140-6736(89)90184-0.

32) Delazar A, Reid R, Sarker S. GC-MS analysis of the essential oil from the oleoresin of Pistacia atlantica var. mutica. Chem Nat Compd. 2004; 40(1): 24-7. doi: 10.1023/B:CONC.0000025459.72590.9e.

33) Olausson EA, Störsrud S, Grundin H, Isaksson M, Attvall S, Simrén M. A small particle size diet reduces upper gastrointestinal symptoms in patients with diabetic gastroparesis: a randomized controlled trial. Am J Gastroenterol. 2014; 109(3): 375-85. doi: 10.1038/ajg.2013.453. PMID: 24419482.

34) Kartalis A, Didagelos M, Georgiadis I, Benetos G, Smyrnioudis N, Marmaras H, et al. Effects of Chios mastic gum on cholesterol and glucose levels of healthy volunteers: A prospective, randomized, placebo- 
controlled, pilot study (CHIOS-MASTIHA). Eur J Prev Cardiol. 2016; 23(7): 722-9. doi: 10.1177/2047487315603186.

35) Choi KM, Gibbons SJ, Nguyen TV, Stoltz GJ, Lurken MS, Ordog T, et al. Heme oxygenase-1 protects interstitial cells of Cajal from oxidative stress and reverses diabetic gastroparesis. Gastroenterology. 2008; 135(6): 2055-64. doi: 10.1053/j.gastro.2008.09.003. PMID: 18926825 PMCID: PMC2796242.

36) Sun J. D-Limonene: safety and clinical applications. Altern Med Rev. 2007; 12(3): 259. PMID: 18072821.

37) Singh B, Sharma RA. Plant terpenes: defense responses, phylogenetic analysis, regulation and clinical applications. 3 Biotech. 2015; 5(2): 129-51. doi: 10.1007/s13205-014-0220-2.

38) Soni S. Effect of Cinnamomum Zeylenicum Nees Bark Oil on Drug Induced Diabetic Gastroparesis in Rats. AJBPS. 2012; 2(9).

39) Benhammou N, Bekkara FA, Panovska TK. Antioxidant and antimicrobial activities of the Pistacia lentiscus and Pistacia atlantica extracts. Afr J Pharm Pharmacol. 2008; 2(2): 22-8.

40) Saeb M, Nazifi S, Yavari M. Studies on the effects of turpentine oil on the serum concentration of lipids and lipoproteins of male rabbits. IJEM. 2005; 7(1): 73-8.

41) Kasabri V, Afifi FU, Hamdan I. In vitro and in vivo acute antihyperglycemic effects of five selected indigenous plants from Jordan used in traditional medicine. J Ethnopharmacol. 2011; 133(2): 888-96. doi: 10.1016/j.jep.2010.11.025. PMID: 21093568. 